\title{
Integration of chronic disease prevention and management services into primary care: a pragmatic randomized controlled trial (PR1MaC)
}

\author{
Martin Fortin MD MSc, Maud-Christine Chouinard RN PhD, Marie-France Dubois PhD, Martin \\ Bélanger MD, José Almirall MD PhD, Tarek Bouhali MD, Maxime Sasseville RN
}

\section{Abstract}

Background: Chronic disease prevention and management programs are usually single-disease oriented. Our objective was to evaluate an intervention that targeted multiple chronic conditions and risk factors.

\begin{abstract}
Methods: We conducted a pragmatic randomized controlled trial involving patients aged 18-75 years with at least 1 of the targeted chronic conditions or risk factors from 8 primary care practices in the Saguenay region of Quebec, Canada, to evaluate an intervention that included self-management support and patient-centred motivational approaches. Self-management (primary outcome) was evaluated using the Health Education Impact Questionnaire (heiQ). Secondary outcomes included self-efficacy, health-related quality of life, psychological distress and health behaviours.
\end{abstract}

Results: Three hundred thirty-two patients were recruited and randomly assigned ( $n=166$ for both intervention and control groups) and evaluated after 3 months. The intervention group showed improvement in 6 of the 8 heiQ domains: health-directed behaviour (relative risk [RR] 1.71, 95\% confidence interval [Cl] 1.13 to 2.59$)$, emotional well-being (RR $1.73,95 \% \mathrm{Cl} 1.07$ to 2.79$)$, self-monitoring and insight (RR $2.40,95 \% \mathrm{Cl} 1.19$ to 4.86 ), constructive attitudes and approaches (RR $2.40,95 \% \mathrm{Cl} 1.37$ to 4.21 ), skill and technique acquisition ( $\mathrm{RR} 1.70,95 \% \mathrm{Cl} 1.14$ to 2.53 ), and health service navigation (RR $1.93,95 \% \mathrm{Cl} 1.08$ to 3.47 ). Improvement was also observed in the Physical Component Summary $(p=0.017)$ and the Single Index $(p=0.041)$ of the 12-Item Short Form Health Survey (version 2). The intervention group improved in fruit and vegetable consumption (odds ratio [OR] 2.36, 95\% $\mathrm{Cl} 1.41$ to 3.95 ) and physical activity (OR $3.81,95 \% \mathrm{Cl} 1.65$ to 8.76 ). One-year improvement was maintained in the intervention group for several outcomes.

Interpretation: It is possible to implement an intervention integrating chronic disease prevention and management services into primary care settings. We obtained positive and promising results using this intervention. Trial registration: ClinicalTrials.gov, no.: NCT01319656.

hronic conditions are the most common problems in health care and the leading causes of death globally. ${ }^{1}$ Acute communicable diseases have given way to chronic conditions such as arthritis, diabetes, and cardiovascular and respiratory diseases that will impose an even greater burden in the future. ${ }^{2}$ The needs of patients with these diseases are usually complex and are challenging to manage. For this reason, many chronic disease prevention and management (CDPM) programs have been designed with the aim of improving outcomes in these patients. CDPM programs targeting diabetes, ${ }^{3-7}$ asthma, ${ }^{8,9}$ heart diseases, ${ }^{10-12}$ depression, ${ }^{13-15}$ chronic obstructive lung disease (COPD), ${ }^{16,17}$ obesity, ${ }^{18,19}$ kidney disease, ${ }^{20}$ dyslipidemia, ${ }^{21}$ hypertension $^{22}$ and chronic pain ${ }^{23}$ have been shown to be effective in improving outcomes such as hospital admissions, costs, adherence to medication, disease control, use of health services, quality of life and mortality. However, these studies were conducted in different settings and were based on single diseases.

Interventions oriented toward single diseases take little account of the multiple morbidities experienced by most patients in primary care. To date, the appropriateness of using

Competing interests: None declared.

This article has been peer reviewed.

Correspondence to: Martin Fortin, Martin.Fortin@usherbrooke.ca CMAJ Open 2016. DOI:10.9778/cmajo.20160031 
multidisciplinary professionals in the context of CDPM programs addressing several conditions has been scarcely studied; however, a few studies have reported mixed but promising results. ${ }^{24-26}$

We introduce a pragmatic innovation involving the adaptation and integration of CDPM services for multiple diseases into the primary care setting and propose an innovative combination of strategies to evaluate the effects and the implementation of this intervention in primary care practices. We wanted to test whether it was possible to implement an intervention integrating multiple disease-oriented CDPM services into the primary care setting. We hypothesized that patients receiving the intervention would report better self-management, empowerment and self-efficacy and would show reduced health-risk behaviours. ${ }^{27}$

\section{Methods}

\section{Settings}

We conducted our study (Adaptation, implantation et évaluation d'une intervention d'intégration des services de réadaptation en maladies chroniques aux soins de 1re ligne [Adapting and integrating chronic disease prevention and management services into primary care settings], $\mathrm{PR} 1 \mathrm{MaC}$ ) in 8 primary care practices in the Saguenay region of Quebec, Canada. Primary care physicians in Quebec mainly work in 2 types of organizations: Group practices (involving a group of primary care physicians working in a team) and Family Medicine Groups (new organizations in which primary care physicians work with nurses in various degrees of collaboration and share the same patients and medical files). Four Family Medicine Groups and 4 solo practices were selected based on geographic localization in the same region and on the population of patients they are serving. The purpose was to ensure a certain level of variation in the cohort.

\section{Participants}

Patients were referred to the research team by their primary care providers to assess eligibility, obtain informed consent and receive the intervention. Patients had to be between 18 and 75 years of age and present with at least 1 of the following chronic conditions or risk factors: diabetes, cardiovascular disease, COPD, asthma, tobacco smoking, obesity, hyperlipidemia, prediabetes, sedentary lifestyle or any combination of these. Patients were required to be fluent in written and spoken French. All study documents and tools, including questionnaires and interview guides, were developed in French.

\section{Intervention}

Detailed information on the intervention has been published elsewhere $^{27}$ and is also provided in Appendix 1 (available at www.cmajopen.ca/content/4/4/E588/suppl/DC1). The principles guiding the intervention were based on self-management support and health education, a patient-centred approach, motivational approach and interprofessional collaboration. For each patient, the intervention started with a preliminary clinical evaluation by a trained nurse. The nurse then designed an individualized intervention plan in collaboration with the patient that could include encounters with 1 or more CDPM professionals in the following disciplines: nursing, physical activity, nutrition, respiratory therapy and smoking cessation therapy. The intervention plan was based on the patient's objectives as identified at the first encounter but could be further adapted by any professional in each discipline involved. Fidelity to the processes was ensured by regular contact with the CDPM professionals. Each intervention was supported by printed information and other educational material to help maintain patient engagement between visits. Intervention at the patient level was individualized and educational in nature, was given over a 3 -month period at the most and consisted of at least 3 individual encounters with trained CDPM professionals. Interventions were done by CDPM professionals who were recruited and trained by the research team and travelled from 1 organization to the other to deliver the services.

\section{Study design}

The effectiveness of this pragmatic intervention was assessed using a combination of 3 experimental designs.

\section{Pragmatic randomized trial}

Participants reported sociodemographic data and completed an initial set of questionnaires at baseline. Patients were then randomly assigned to receive an immediate (intervention group, group A) or delayed intervention (control group, group B) that occurred 3 months after baseline. To prevent selection bias, a rigorous randomization process with allocation concealment was followed. To generate a random allocation sequence, 2 people unrelated to the study prepared sealed and unmarked opaque envelopes containing cards with either a letter A (intervention) or B (control) in equal numbers. Envelopes were shuffled several times to generate a random sequence of assignments. A research assistant was responsible for the random group assignment of patients. To prevent subversion of the allocation sequence, every time the research assistant received a baseline questionnaire completed by mail, he called the patient, opened 1 envelope to notify the patient of their allocation to a group, and wrote the information in the patient's file. Blinding was not achievable, because both patients and health care providers knew who was involved in each group.

Three months after baseline, patients in both groups completed a second evaluation (Figure 1).

\section{Before-and-after design}

To document the effectiveness of the intervention at 1 year, patients in the intervention group were reassessed a third time using the same measurement tools (Figure 1).

\section{Controlled before-and-after design}

We also used a controlled before-and-after design with a comparative cohort used to evaluate 1-year effectiveness. All patients who received the intervention (immediate and delayed) were included in this analysis. The control cohort 
(group C) was from the Program of Research on the Evolution of a Cohort Investigating Health System Effects (PRECISE) research program. ${ }^{28}$ The PRECISE program recruited a cohort of adults aged 25-75 years who were followed for 4 years with no intervention. The target population was community-dwelling adults undifferentiated by disease, who did not have any major cognitive impairment and were able to respond to written and oral questions in English or French. Participants were randomly selected from the geographic boundaries of 4 regions of Quebec. Patients from this observational cohort (2198 participants) were pair-matched with all patients in our study (intervention and control groups) by age $( \pm 5 \mathrm{yr}$ ), sex, number of chronic diseases, main diagnosis and other diagnoses when possible. Groups were compared on the basis of changes over 1 year (Figure 1).

\section{Variables and outcome measures}

At baseline, we collected participant sociodemographic data including sex, age, education, income, marital status and occu- pation in French. We also measured the illness burden using the Disease Burden Morbidity Assessment tool. ${ }^{29,30}$

We evaluated the primary outcome, self-management, using the Health Education Impact Questionnaire (heiQ), ${ }^{31,32}$ which provides a broad profile of the potential impacts of patient education interventions and is specifically designed to be applied across a large range of chronic conditions. The heiQ measures 8 different domains related to self-management. Each domain is standardized to range from 1 to 4 , and baseline and follow-up data are compared to determine the achievement of meaningful changes in each domain. The questionnaire has high construct validity and good reliability. ${ }^{32}$ The development and validation of the heiQ, including the French version, has been described previously. ${ }^{32,33}$

Secondary outcomes used to assess the effectiveness of the intervention were self-efficacy, health-related quality of life, psychological distress and lifestyle factors. We evaluated selfefficacy using the Self-Efficacy for Managing Chronic Disease 6-Item Scale. ${ }^{34,35}$

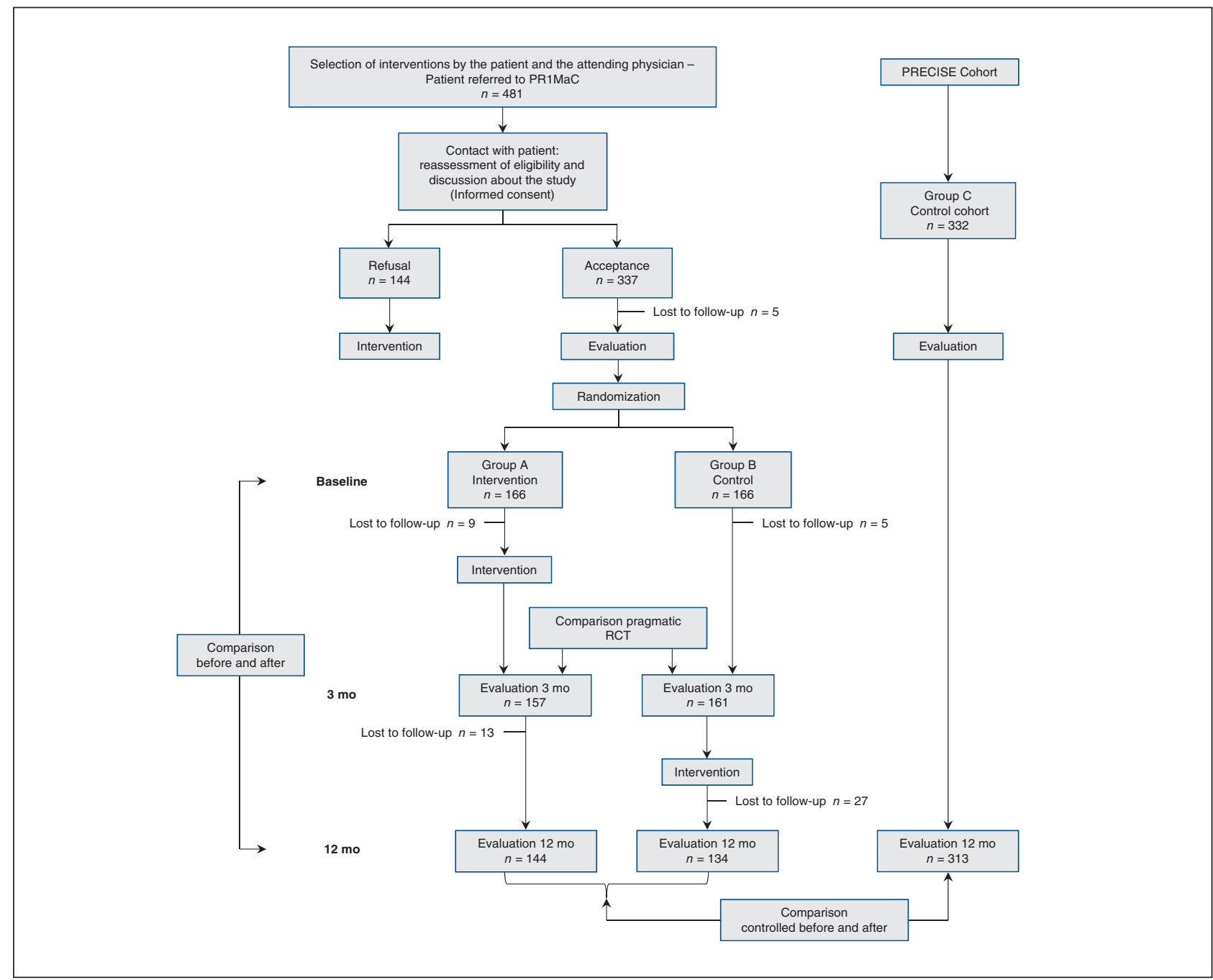

Figure 1: Flow diagram for the PR1MaC study. PR1MaC = Adaptation, implantation et évaluation d'une intervention d'intégration des services de réadaptation en maladies chroniques aux soins de 1re ligne (Adapting and integrating chronic disease prevention and management services into primary care settings), RCT = randomized controlled trial. 
We measured health-related quality of life (HRQoL) using the 12-Item Short-Form Health Survey (SF-12 version 2). ${ }^{36}$ The measurement includes the components of physical functioning and mental health. We also calculated a preferencebased single index of quality of life (6-dimensional health state classificaton, SF-6D) by applying a scoring method that contains 6 dimensions of the SF-12 (version 2). ${ }^{37}$ Higher values indicate better health status in all measures of HRQoL.

We assessed psychological distress using the Kessler Psychological Distress Scale (K6) ${ }^{38,39}$ Scores range from 0 to 24; we considered scores of 13 or higher as indicating the presence of psychological distress.

Finally, we used 3 self-reported lifestyle indicators: fruit and vegetable consumption, physical activity and body mass index (BMI) derived from self-reported weight and height. The criteria for classifying participants as achieving recommended behavioural targets were the following: consumption of 5 portions or more of fruit and vegetables daily $(1$ portion $=$ $4 \mathrm{oz}$ or $125 \mathrm{~mL}$ ), being physically active (20-30 min of exercise 4 times/wk) and normal BMI $\left(18.5-24.9 \mathrm{~kg} / \mathrm{m}^{2}\right) .^{40}$ All the above outcomes were measured at baseline, after 3 months and after 1 year via self-report.

\section{Sample size and statistical power}

We calculated the required sample size 326 participants for the randomized clinical trial for the main outcome (the percentage of patients who improved as measured by the heiQ) with a 2 -sided $\alpha=0.05$ and $80 \%$ power, and we accounted for a drop out rate of $15 \%$. We estimated that an effect size of 0.34 would be detectable for continuous scores.

\section{Data analysis}

\section{Randomized trial}

To evaluate meaningful individual changes in the heiQ domains, we used the classical Jacobsen and Truax Reliable Change Index, with a cut-off point greater than $1.65 .{ }^{41}$ To determine that a change was meaningful, we corrected each individual difference in score on each domain by dividing the difference by the standard error (SE) of the difference. If the corrected difference exceeded the 1.65 threshold, we considered this difference meaningful (reliable). The cut-off point of greater than 1.65 is equivalent to a probability of $10 \%$ of an approximately equal balance between errors in the direction of classifying a participant as "reliably changed" when the observed change was actually because of error, and errors in the direction of classifying an individual as "not changed" when the observed change was actually reliable. For each of the 8 domains of the heiQ, we compared the percentage of subjects with a reliable improvement in each group (intervention v. control) using relative risk (RR) with a $95 \%$ confidence interval (CI). Primary analysis used intention to treat.

To evaluate intervention effects on quantitative outcome, we compared the scores of the intervention and control groups after 3 months with an analysis of covariance (ANCOVA) adjusted for baseline scores. ${ }^{42}$ Unstandardized (differences between means with 95\% CI), adjusted and stan- dardized (Cohen's effect size d) differences between means are also reported. For dichotomous outcomes, we compared intervention and control groups using a logistic regression analysis adjusted for baseline and report odds ratios (ORs). We undertook a complete case analysis because there were only a few missing outcomes after 3 months $(<5 \%){ }^{43}$

\section{Before-and-after design}

To test the effectiveness of the intervention within the intervention group over 1 year, we used the paired $t$ test for continuous variables and the McNemar test for categorical variables.

\section{Controlled before-and-after design}

For comparisons with group C (PRECISE) over 1 year, we used ANCOVA or logistic regression analysis and adjusted for scores at baseline.

We used IBM SPSS Statistics 20 for all data analyeses. In all statistical tests, we tested for significance at the $5 \%$ level. Cohen's d effect size ${ }^{44}$ was calculated with Microsoft Office Excel 2007 using the pooled standard deviation (SD) for the samples in the calculation.

This study received ethics approval from the Research Ethics Board of the Centre de santé et de services sociaux de Chicoutimi.

\section{Results}

Figure 1 provides flowchart diagram for the 3 different experimental designs. Table 1 shows the baseline demographics and clinical characteristics of participants for each group. Among patients in the intervention group, mean time for the intervention was 220 (SD 77) minutes and a mean of 2.4 (SD 1.2) visits with CDPM professionals (range $0-5$ visits; there were patients who had encounters with more than 1 CDPM professional).

\section{Randomized trial}

The recruitment and follow-up started in November 2011 and ended in July 2012. A total of 481 eligible patients were referred by primary care providers; 144 patients received the intervention but refused to participate in the research. All patients were contacted to reassess their eligibility, to discuss the study and to obtain their informed consent if they agreed to participate in the study. Patients who refused to participate received the intervention offered by their primary care provider (Figure 1), but they were not included as particpants. Of the 337 patients who initially agreed to participate, 5 declined before completing the baseline questionnaires. The remaining 332 patients were randomnly assigned (166 to the intervention group and 166 to the control group). The number of participants from each practice ranged from 9 to 80 . Nine patients from the intervention group and 5 patients from the control group were lost to follow-up after 3 months. Therefore, 157 patients from the intervention group and 161 patients from the control group underwent the evaluation after 3 months. 


\section{OPEN}

Research

Scores for heiQ in the intervention and control groups at baseline and after 3 months are shown in Table 2. Mean absolute values after 3 months were significantly different from baseline in 6 of the 8 domains of heiQ: health-directed behaviour, emotional well-being, self-monitoring and insight, constructive attitudes and approaches, skill and technique acquisition, and health service navigation. Figure 2 shows the relative risk of a reliable improvement from baseline to 3 months in the intervention group compared with the control group for each domain of self-management. Point estimates varied from 1.15 to 2.4 , and the lower boundary for 95\% CI was greater than 1 in the same 6 domains of heiQ in which mean absolute values were different from baseline after 3 months. The number of participants used to calculate the percentage of patients who had a reliable improvement in heiQ score in the 2 groups is shown in Appendix 1.

For the other continuous variables (Self-Efficacy for Managing Chronic Disease, Physical Component Summary of SF-12 [version 2], Mental Component Summary of SF-12 [version 2], Single Index of Sf-12 [version 2] and BMI), differences in mean scores between the intervention and control groups were statistically significant for the Physical Component Summary (Appendix 1). Results of the logistic regression analysis for the presence of psychological distress, recommended consumption of fruit and vegetables, and recommended physical activity are shown in Table 3. The intervention group had significantly higher ORs for fruit and vegetable consumption, and physical activity.

\begin{tabular}{|c|c|c|c|}
\hline \multirow[b]{2}{*}{ Characteristic } & \multicolumn{3}{|c|}{ No. of participants $(\%)^{\star}$} \\
\hline & $\begin{array}{l}\text { Intervention } \\
\qquad \begin{array}{l}\text { group } \\
n=166\end{array}\end{array}$ & $\begin{array}{l}\text { Control group } \\
\quad n=166\end{array}$ & $\begin{array}{l}\text { PRECISE } \\
\text { control cohort† } \\
\quad n=332\end{array}$ \\
\hline Age, yr; mean \pm SD & $52.4 \pm 11.6$ & $52.6 \pm 11.6$ & $54.0 \pm 9.9$ \\
\hline No. of chronic diseases, mean \pm SD & $5.1 \pm 2.6$ & $4.8 \pm 2.2$ & $4.8 \pm 2.5$ \\
\hline Illness burden (DBMA score); mean \pm SD & $11.0 \pm 7.7$ & $9.6 \pm 6.3$ & $9.7 \pm 7.5$ \\
\hline Male & $88(53.0)$ & $84(50.6)$ & $174(52.4)$ \\
\hline Multimorbidity ( $\geq 2$ conditions) & $159(95.8)$ & $156(94.0)$ & $313(94.3)$ \\
\hline Multimorbidity ( $\geq 3$ conditions) & $139(83.7)$ & $142(85.5)$ & $271(81.6)$ \\
\hline \multicolumn{4}{|l|}{ Education level } \\
\hline Did not complete high school & $21(12.7)$ & $38(22.9)$ & $78(23.5)$ \\
\hline High school & $58(34.9)$ & $52(31.3)$ & $122(36.7)$ \\
\hline College & $48(28.9)$ & $49(29.5)$ & $73(22.0)$ \\
\hline University & $37(22.3)$ & $27(16.3)$ & $58(17.5)$ \\
\hline Missing data & $2(1.2)$ & - & $1(0.3)$ \\
\hline \multicolumn{4}{|l|}{ Household income, Can\$ } \\
\hline$<20000$ & $20(12.0)$ & $21(12.7)$ & $50(15.1)$ \\
\hline $20000-49999$ & $58(34.9)$ & 65 (39.2) & $132(39.8)$ \\
\hline$\geq 50000$ & $84(50.6)$ & $77(46.4)$ & $145(43.7)$ \\
\hline Missing data & $4(2.4)$ & $3(1.8)$ & $5(1.5)$ \\
\hline \multicolumn{4}{|l|}{ Marital status } \\
\hline Married & $114(68.7)$ & $131(78.9)$ & $219(66.0)$ \\
\hline Single or divorced & $42(25.3)$ & $29(17.4)$ & 98 (29.56) \\
\hline Widowed & $10(6.0)$ & $6(3.6)$ & $15(4.5)$ \\
\hline \multicolumn{4}{|l|}{ Employment } \\
\hline Employed & $97(58.4)$ & $95(57.2)$ & $167(50.3)$ \\
\hline Unemployed & $23(13.9)$ & $30(18.1)$ & $71(21.4)$ \\
\hline Retired & $44(26.5)$ & $40(24.1)$ & $94(28.3)$ \\
\hline Missing data & $2(1.2)$ & $1(0.6)$ & - \\
\hline \multicolumn{4}{|c|}{$\begin{array}{l}\text { Note: DBMA = Disease Burden Morbidity Assessment, PRECISE = Program of Research on the Evolution of a } \\
\text { Cohort Investigating Health System Effects, SD = standard deviation. } \\
\text { *Unless otherwise specified. } \\
\text { †Control group used in the controlled before-and-after design. }\end{array}$} \\
\hline
\end{tabular}




\section{Before-and-after design}

A summary including the results for all variables of the beforeand-after design for participants from the intervention group is shown in Table 4. The analysis included only those participants with data at baseline, after 3 months and after 1 year. After 3 months, changes in all domains of the heiQ were significantly different from baseline, with an effect size ranging from small to medium (between 0.20 and 0.52 ). After 1 year, changes continued to be significantly different from baseline except for the health service navigation domain. Figure 3 shows the changes in each domain of the heiQ over one year. The percentage of patients in the Intervention group who improved in different domains was between 16\% (23/143) and 36\% (50/140).

\section{Controlled before-and-after design}

We matched the 332 participants in this study with 332 particpants in the PRECISE (control cohort, group C) study by age, sex, number of chronic diseases, main diagnosis and other diagnoses when possible. Demographic and clinical characteristics of group $\mathrm{C}$ and $\mathrm{PR} 1 \mathrm{MaC}$ participants at baseline are shown in Table 1 . Results over 1 year, with significant differences in the Physical Component Summary and BMI that favour the intervention, are shown in Table 5.

\section{Interpretation}

As part of the intervention in this study, we adapted and implemented the integration of disease prevention and management services into primary health care for 4 chronic conditions and their risk factors. After 3 months, the intervention showed some benefit in 6 out of the 8 domains of self-management measured by the heiQ, both in terms of absolute mean values and RR analysis, compared with the control group. However, the percentage of patients in the intervention group who improved in different domains varied between $16 \%$ and $36 \%$ (i.e., they were not the majority in any domain). Our interpretation of this is that there is still room for improvement and making the intervention more effective. Recently, Coventry and colleagues ${ }^{45}$ published the results of a cluster randomized controlled trial for patients with depression and comorbid diabetes or cardiovascular disease in which the heiQ was used as a secondary outcome. As in our study, Coventry and colleagues did not observe significant improvement in the domains of positive and active engagement in life, and social integration and support.

The evaluation of secondary outcomes in our study also showed modest but beneficial effects of the intervention in fruit and vegetable consumption, physical activity and the physical component of quality of life. In general, after 1 year, improvements were still present. BMI showed a modest but significant improvement after 1 year. Psychological distress did not change. This lack of change could reflect either that the length of the interventions was too short or that the elements behind this situation were not among those targeted by the intervention. The prevalence of recommended physical activity significantly improved at 3 months but decreased over 1 year to a level equivalent to baseline. This may indicate a

Table 2: Participant scores at baseline and after 3 months for the heiQ, by self-management domain

\begin{tabular}{|c|c|c|c|c|c|c|c|c|c|}
\hline \multirow[b]{2}{*}{ Domain (heiQ) } & \multirow[b]{2}{*}{ Group } & \multicolumn{2}{|c|}{ At baseline } & \multicolumn{2}{|c|}{ After 3 mo } & \multicolumn{2}{|c|}{ Mean difference, baseline v. 3 mo $(95 \% \mathrm{Cl})$} & \multirow{2}{*}{$\begin{array}{l}\text { Cohen's } \\
\text { d }\end{array}$} & \multirow[b]{2}{*}{$p \ddagger$} \\
\hline & & $n$ & Mean \pm SD & $n$ & Mean \pm SD & Within group* & Between group $†$ & & \\
\hline \multirow{2}{*}{$\begin{array}{l}\text { Health-directed } \\
\text { behaviour }\end{array}$} & Intervention & 162 & $2.61 \pm 0.73$ & 153 & $2.96 \pm 0.63$ & $0.32(0.21$ to 0.43$)$ & \multirow[t]{2}{*}{$0.20(0.08$ to 0.32$)$} & \multirow[t]{2}{*}{0.27} & \multirow[t]{2}{*}{0.001} \\
\hline & Control & 163 & $2.66 \pm 0.78$ & 156 & $2.78 \pm 0.72$ & $0.11(0.03$ to 0.21$)$ & & & \\
\hline \multirow{2}{*}{$\begin{array}{l}\text { Positive and active } \\
\text { engagement in life }\end{array}$} & Intervention & 165 & $3.10 \pm 0.54$ & 156 & $3.24 \pm 0.51$ & $0.13(0.06$ to 0.20$)$ & \multirow[t]{2}{*}{$0.04(-0.04$ to 0.12$)$} & \multirow[t]{2}{*}{0.12} & \multirow[t]{2}{*}{0.319} \\
\hline & Control & 165 & $3.10 \pm 0.54$ & 158 & $3.18 \pm 0.50$ & 0.10 (0.04 to 0.15$)$ & & & \\
\hline \multirow[t]{2}{*}{ Emotional well-being } & Intervention & 160 & $2.68 \pm 0.64$ & 149 & $2.96 \pm 0.60$ & $0.27(0.18$ to 0.36$)$ & \multirow[t]{2}{*}{$0.13(0.03$ to 0.23$)$} & \multirow[t]{2}{*}{0.19} & \multirow[t]{2}{*}{0.012} \\
\hline & Control & 160 & $2.73 \pm 0.63$ & 153 & $2.85 \pm 0.56$ & $0.13(0.06$ to 0.19$)$ & & & \\
\hline \multirow{2}{*}{$\begin{array}{l}\text { Self-monitoring and } \\
\text { insight }\end{array}$} & Intervention & 159 & $3.03 \pm 0.41$ & 149 & $3.23 \pm 0.38$ & $0.18(0.11$ to 0.25$)$ & \multirow[t]{2}{*}{0.14 (0.06 to 0.22$)$} & \multirow[t]{2}{*}{0.39} & \multirow[t]{2}{*}{0.001} \\
\hline & Control & 160 & $3.01 \pm 0.41$ & 154 & $3.07 \pm 0.44$ & 0.06 (0.01 to 0.11$)$ & & & \\
\hline \multirow{2}{*}{$\begin{array}{l}\text { Constructive attitudes } \\
\text { and approaches }\end{array}$} & Intervention & 163 & $3.07 \pm 0.48$ & 153 & $3.22 \pm 0.47$ & 0.15 (0.08 to 0.22$)$ & \multirow[t]{2}{*}{0.09 (0.01 to 0.18$)$} & \multirow[t]{2}{*}{0.11} & \multirow[t]{2}{*}{0.035} \\
\hline & Control & 161 & $3.13 \pm 0.46$ & 155 & $3.17 \pm 0.48$ & $0.03(-0.02$ to 0.09$)$ & & & \\
\hline \multirow{2}{*}{$\begin{array}{l}\text { Skill and technique } \\
\text { acquisition }\end{array}$} & Intervention & 163 & $2.83 \pm 0.51$ & 153 & $3.09 \pm 0.45$ & $0.25(0.17$ to 0.32$)$ & \multirow[t]{2}{*}{$0.14(0.06$ to 0.23$)$} & \multirow[t]{2}{*}{0.31} & \multirow[t]{2}{*}{0.001} \\
\hline & Control & 161 & $2.86 \pm 0.50$ & 156 & $2.95 \pm 0.45$ & $0.10(0.04$ to 0.17$)$ & & & \\
\hline \multirow{2}{*}{$\begin{array}{l}\text { Social integration and } \\
\text { support }\end{array}$} & Intervention & 164 & $2.98 \pm 0.53$ & 154 & $3.09 \pm 0.54$ & $0.10(0.04$ to 0.17$)$ & \multirow[t]{2}{*}{$0.07(-0.01$ to 0.16$)$} & \multirow[t]{2}{*}{0.19} & \multirow[t]{2}{*}{0.089} \\
\hline & Control & 161 & $2.95 \pm 0.54$ & 156 & $2.99 \pm 0.53$ & $0.05(-0.02$ to 0.11$)$ & & & \\
\hline Health service & Intervention & 165 & $3.27 \pm 0.41$ & 154 & $3.38 \pm 0.42$ & $0.10(0.03$ to 0.18$)$ & $0.12(0.03$ to 0.20$)$ & 0.35 & 0.005 \\
\hline & Control & 166 & $3.26 \pm 0.42$ & 160 & $3.23 \pm 0.45$ & $-0.003(-0.06$ to 0.06$)$ & & & \\
\hline
\end{tabular}


need to reinforce the message at follow-up. A recent systematic review and meta-analysis reported that interventions to promote physical activity lead to improvements in physical activity at 12 months. ${ }^{46}$ Longer sustainability was unclear. ${ }^{46}$

The score for self-efficacy for managing chronic disease showed no significant difference between intervention and control groups. A closer look at the results of this variable showed that mean values were high at baseline in both groups, with little room for improvement. The statistically significant improvement observed in the physical component of quality of life of the experimental group was of limited clinical importance. ${ }^{47}$

Other studies of multidisciplinary specialized professionals have been conducted in the context of single conditions, includ-

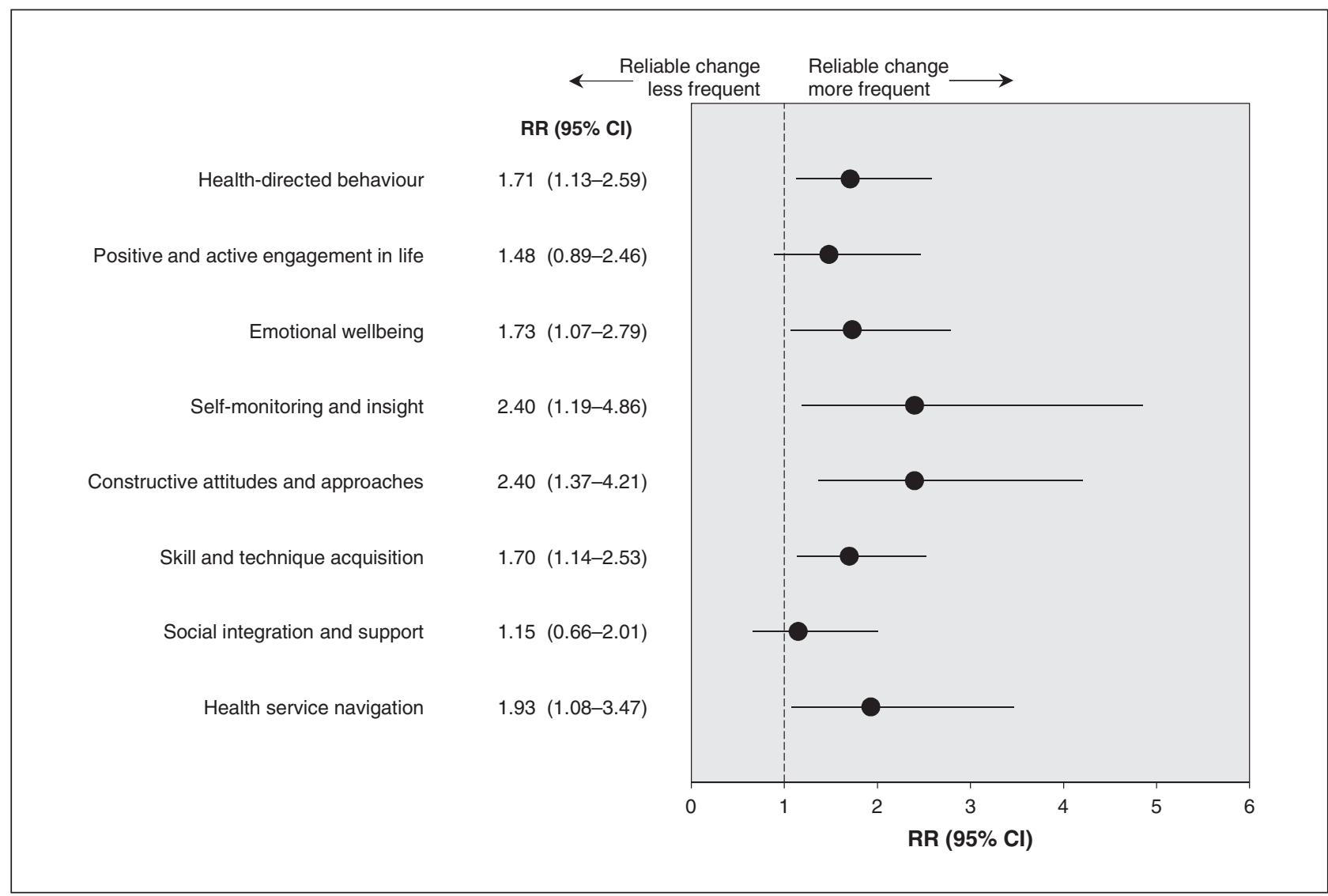

Figure 2: Relative risks (RRs) (intervention group v. control group) and 95\% confidence intervals (Cls) of a reliable improvement at 3 months compared with baseline, by domain of self-management. Values greater than 1.0 indicate more patients in the intervention group had reliable improvement in a domain of self-management compared with the control group. The difference between the 2 groups is significant when the value of no difference $(\mathrm{RR}=1.0)$ is not included in the $\mathrm{Cl}$.

\begin{tabular}{|c|c|c|c|c|}
\hline Variable & Group & $\begin{array}{l}\text { No. of participants at } \\
\text { baseline/total no. of } \\
\text { participants (\%) }\end{array}$ & $\begin{array}{l}\text { No. of participants } \\
\text { after } 3 \text { mo/total no. } \\
\text { of participants (\%) }\end{array}$ & $\begin{array}{l}\text { Adjusted OR } \\
(95 \% \mathrm{Cl})\end{array}$ \\
\hline \multirow[t]{2}{*}{ Psy. distress } & Intervention & $16 / 154(10.4)$ & 8/154 (5.2) & \multirow[t]{2}{*}{0.84 (0.29 to 2.45$)$} \\
\hline & Control & 15/161 (9.3) & 9/158 (5.7) & \\
\hline \multirow[t]{2}{*}{ Fruit and veg. } & Intervention & 49/155 (31.6) & $83 / 151$ (55.0) & \multirow[t]{2}{*}{2.36 (1.41 to 3.95$)$} \\
\hline & Control & $50 / 161(31.1)$ & $61 / 160(38.1)$ & \\
\hline \multirow[t]{2}{*}{ Phys. activity } & Intervention & $15 / 155$ (9.7) & $32 / 154(20.8)$ & \multirow[t]{2}{*}{3.81 (1.65 to 8.76$)$} \\
\hline & Control & 22/161 (13.7) & 18/159 (11.3) & \\
\hline
\end{tabular}


Table 4: Intervention group results for before-and-after design portion of the PR1MaC study at baseline, after 3 mo and after $12 \mathrm{mo}$, by variable; and relative risk, by variable

\begin{tabular}{|c|c|c|c|c|c|c|c|c|c|}
\hline \multirow[b]{2}{*}{ Variable* $^{*}$} & \multicolumn{3}{|c|}{ Mean \pm SD } & \multicolumn{3}{|c|}{ Baseline v. 3 mo } & \multicolumn{3}{|c|}{ Baseline v. $12 \mathrm{mo}$} \\
\hline & At baseline & After 3 mo & After 12 mo & $\begin{array}{c}\text { Mean difference } \\
(95 \% \mathrm{Cl}) \dagger\end{array}$ & $\begin{array}{l}\text { Cohen's } \\
\text { d }\end{array}$ & $p$ & $\begin{array}{c}\text { Mean difference } \\
(95 \% \mathrm{Cl}) \ddagger\end{array}$ & $\begin{array}{l}\text { Cohen's } \\
\text { d }\end{array}$ & $p$ \\
\hline $\begin{array}{l}\text { Health directed } \\
\text { behaviour, } \\
n=140\end{array}$ & $2.62 \pm 0.75$ & $2.96 \pm 0.64$ & $2.93 \pm 0.64$ & $\begin{array}{c}0.36 \\
(0.24 \text { to } 0.47)\end{array}$ & 0.49 & $<0.001$ & $\begin{array}{c}0.32 \\
(0.20 \text { to } 0.45)\end{array}$ & 0.45 & $<0.001$ \\
\hline $\begin{array}{l}\text { Positive and } \\
\text { active } \\
\text { engagement in } \\
\text { life, } n=142\end{array}$ & $3.12 \pm 0.53$ & $3.25 \pm 0.51$ & $3.29 \pm 0.49$ & $\begin{array}{c}0.15 \\
(0.07 \text { to } 0.23)\end{array}$ & 0.25 & $<0.001$ & $\begin{array}{c}0.16 \\
(0.08 \text { to } 0.24)\end{array}$ & 0.33 & $<0.001$ \\
\hline $\begin{array}{l}\text { Emotional } \\
\text { well-being, } \\
n=138\end{array}$ & $2.69 \pm 0.65$ & $2.95 \pm 0.60$ & $2.98 \pm 0.64$ & $\begin{array}{c}0.26 \\
(0.16 \text { to } 0.37)\end{array}$ & 0.42 & $<0.001$ & $\begin{array}{c}0.30 \\
(0.18 \text { to } 0.40)\end{array}$ & 0.45 & $<0.001$ \\
\hline $\begin{array}{l}\text { Self-monitoring } \\
\text { and insight, } \\
n=137\end{array}$ & $3.06 \pm 0.41$ & $3.24 \pm 0.37$ & $3.26 \pm 0.37$ & $\begin{array}{c}0.18 \\
(0.10 \text { to } 0.28)\end{array}$ & 0.46 & $<0.001$ & $\begin{array}{c}0.21 \\
(0.13 \text { to } 0.28)\end{array}$ & 0.51 & $<0.001$ \\
\hline $\begin{array}{l}\text { Constructive } \\
\text { attitudes and } \\
\text { approaches, } \\
n=142\end{array}$ & $3.09 \pm 0.47$ & $3.24 \pm 0.46$ & $3.27 \pm 0.47$ & $\begin{array}{c}0.15 \\
(0.06 \text { to } 0.24)\end{array}$ & 0.32 & $<0.001$ & $\begin{array}{c}0.17 \\
(0.08 \text { to } 0.26)\end{array}$ & 0.38 & $<0.001$ \\
\hline $\begin{array}{l}\text { Skill and } \\
\text { technique } \\
\text { acquisition, } \\
n=141\end{array}$ & $2.85 \pm 0.50$ & $3.09 \pm 0.43$ & $3.12 \pm 0.48$ & $\begin{array}{c}0.26 \\
(0.18 \text { to } 0.35)\end{array}$ & 0.52 & $<0.001$ & $\begin{array}{c}0.29 \\
(0.20 \text { to } 0.38)\end{array}$ & 0.55 & $<0.001$ \\
\hline $\begin{array}{l}\text { Social } \\
\text { integration and } \\
\text { support, } \\
n=142\end{array}$ & $2.98 \pm 0.54$ & $3.09 \pm 0.54$ & $3.13 \pm 0.56$ & $\begin{array}{c}0.11 \\
(0.03 \text { to } 0.18)\end{array}$ & 0.20 & 0.003 & $\begin{array}{c}0.13 \\
(0.06 \text { to } 0.21)\end{array}$ & 0.27 & $<0.001$ \\
\hline $\begin{array}{l}\text { Health service } \\
\text { navigation, } \\
n=143\end{array}$ & $3.28 \pm 0.41$ & $3.39 \pm 0.42$ & $3.35 \pm 0.44$ & $\begin{array}{c}0.11 \\
(0.02 \text { to } 0.18)\end{array}$ & 0.27 & 0.006 & $\begin{array}{c}0.06 \\
(-0.02 \text { to } 0.14)\end{array}$ & 0.17 & 0.104 \\
\hline $\begin{array}{l}\text { Score SEM-CD, } \\
n=136\end{array}$ & $7.41 \pm 1.82$ & $7.94 \pm 1.57$ & $7.76 \pm 1.94$ & $\begin{array}{c}0.53 \\
(0.25 \text { to } 0.80)\end{array}$ & 0.31 & $<0.001$ & $\begin{array}{c}0.55 \\
(0.26 \text { to } 0.84)\end{array}$ & 0.19 & 0.02 \\
\hline PCS, $n=143$ & $42.4 \pm 9.8$ & $45.8 \pm 9.3$ & $46.7 \pm 9.8$ & $\begin{array}{c}3.5 \\
(2.2 \text { to } 4.8)\end{array}$ & 0.36 & $<0.001$ & $\begin{array}{c}4.2 \\
(2.7 \text { to } 5.6)\end{array}$ & 0.44 & $<0.001$ \\
\hline MCS, $n=143$ & $46.8 \pm 10.9$ & $49.5 \pm 10.1$ & $49.4 \pm 10.2$ & $\begin{array}{c}2.7 \\
(1.4 \text { to } 4.2)\end{array}$ & 0.26 & $<0.001$ & $\begin{array}{c}2.9 \\
(1.2 \text { to } 4.7)\end{array}$ & 0.25 & 0.002 \\
\hline SF-6D, $n=140$ & $0.661 \pm 0.108$ & $0.698 \pm 0.113$ & $0.704 \pm 0.106$ & $\begin{array}{c}0.040 \\
(0.022 \text { to } 0.059)\end{array}$ & 0.34 & $<0.001$ & $\begin{array}{c}0.045 \\
(0.025 \text { to } 0.066)\end{array}$ & 0.40 & $<0.001$ \\
\hline $\mathrm{BMI}, n=132$ & $31.6 \pm 6.7$ & $31.3 \pm 7.5$ & $30.6 \pm 6.8$ & $\begin{array}{c}-0.27 \\
(-0.89 \text { to } 0.66)\end{array}$ & -0.04 & 0.5 & $\begin{array}{c}-0.94 \\
(-1.48 \text { to }-0.46)\end{array}$ & -0.15 & $<0.001$ \\
\hline Variable & & of participants & & $\mathrm{RR}$ & $55 \%$ Cl) & & $\mathrm{RR}$ & $95 \% \mathrm{Cl})$ & \\
\hline $\begin{array}{l}\text { Psy. distress, } \\
n=140\end{array}$ & $15(10.7)$ & $8(5.7)$ & $12(8.6)$ & $0.53(C$ & 23 to 1.22$)$ & & $0.80(0$ & 39 to 1.65$)$ & \\
\hline $\begin{array}{l}\text { Fruit and veg., } \\
n=140\end{array}$ & 48 (34.3) & $79(56.4)$ & $70(50.0)$ & $1.65(1$ & 5 to 2.16$)$ & & $1.46(1$ & 10 to 1.94$)$ & \\
\hline $\begin{array}{l}\text { Phys. activity, } \\
n=143\end{array}$ & $14(9.8)$ & $30(21.0)$ & $23(16.1)$ & $2.14(1$ & 19 to 3.87 ) & & $1.64(0$ & 88 to 3.06$)$ & \\
\hline \multicolumn{10}{|c|}{ 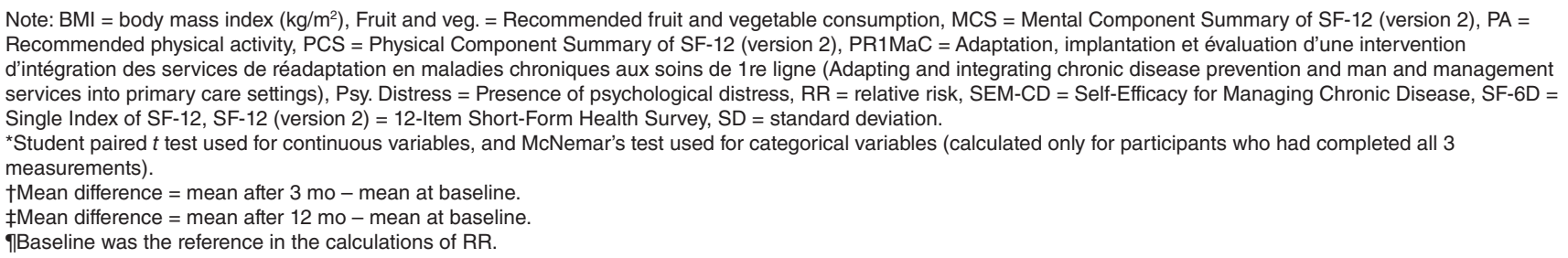 } \\
\hline
\end{tabular}




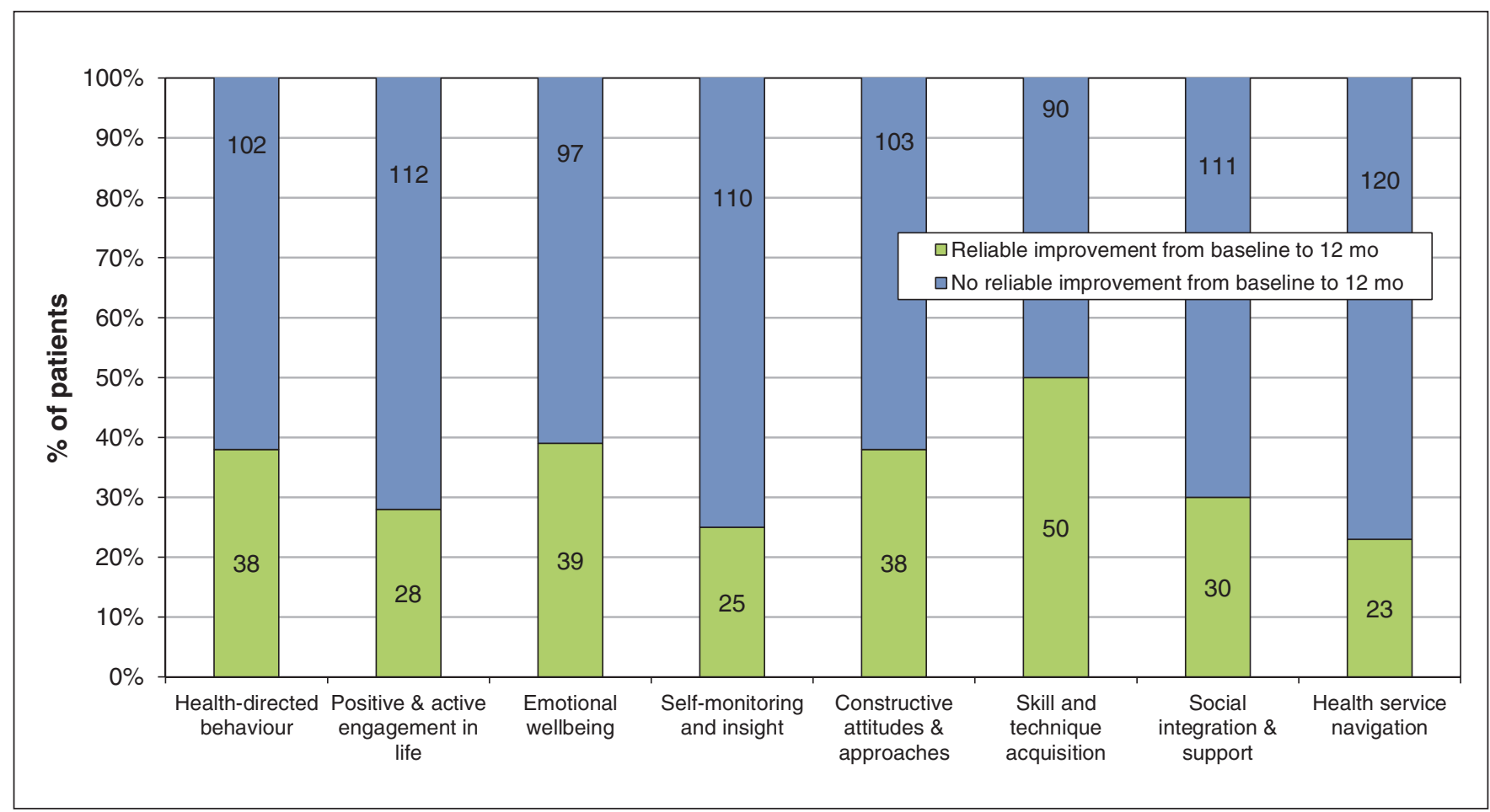

Figure 3: Distribution of changes (improvement or no improvement) in the intervention group after 1 year compared with baseline, by domain of self-management. Values inside the bars show absolute numbers of patients.

Table 5: Controlled before-and-after design: comparison at 1 year

\begin{tabular}{|c|c|c|c|c|c|c|c|c|}
\hline \multirow[b]{3}{*}{ Variable } & \multirow{2}{*}{\multicolumn{2}{|c|}{$\begin{array}{c}\text { PR1MaC } \\
\text { (intervention + control) } \\
\text { Mean } \pm \text { SD }\end{array}$}} & \multirow{2}{*}{\multicolumn{2}{|c|}{$\frac{\text { PRECISE (control cohort) }}{\text { Mean } \pm \text { SD }}$}} & \multirow{2}{*}{\multicolumn{4}{|c|}{ Mean difference $(95 \% \mathrm{Cl})$}} \\
\hline & & & & & & & & \\
\hline & At baseline & After 12 mo & At baseline & After $12 \mathrm{mo}$ & PR1MaC* & PRECISE* $^{*}$ & $\begin{array}{l}\text { PR1MaC v. } \\
\text { PRECISE† }\end{array}$ & $p \ddagger$ \\
\hline PCS & $43.6 \pm 10.3$ & $45.6 \pm 9.7$ & $43.6 \pm 11.7$ & $43.8 \pm 11.3$ & $\begin{array}{c}2.2 \\
(1.3 \text { to } 3.1)\end{array}$ & $\begin{array}{c}0.3 \\
(-0.6 \text { to } 1.2)\end{array}$ & $\begin{array}{c}1.51 \\
(0.41 \text { to } 2.62)\end{array}$ & 0.007 \\
\hline MCS & $47.1 \pm 10.8$ & $49.6 \pm 9.6$ & $47.2 \pm 10.6$ & $48.9 \pm 10.3$ & $\begin{array}{c}2.0 \\
(1.0 \text { to } 3.1)\end{array}$ & $\begin{array}{c}1.6 \\
(0.6 \text { to } 2.5)\end{array}$ & $\begin{array}{c}0.62 \\
(-0.54 \text { to } 1.77)\end{array}$ & 0.295 \\
\hline BMI & $31.8 \pm 7.2$ & $30.7 \pm 7.0$ & $30.6 \pm 6.1$ & $30.6 \pm 6.3$ & $\begin{array}{c}-0.8 \\
(-1.2 \text { to }-0.4)\end{array}$ & $\begin{array}{c}0.1 \\
(-0.2 \text { to } 0.3)\end{array}$ & $\begin{array}{c}-0.83 \\
(-1.29 \text { to }-0.37)\end{array}$ & $<0.001$ \\
\hline Variable & \multicolumn{2}{|c|}{$\begin{array}{l}\text { No. of participants/total no. } \\
\text { of participants (\%) }\end{array}$} & \multicolumn{2}{|c|}{$\begin{array}{l}\text { No. of participants/total } \\
\text { no. of participants (\%) }\end{array}$} & \multicolumn{3}{|c|}{ OR $(95 \% \mathrm{Cl})$} & $p$ \\
\hline Psy. distress & $\begin{array}{c}34 / 330 \\
(10.3)\end{array}$ & $\begin{array}{c}17 / 315 \\
(5.4)\end{array}$ & $\begin{array}{l}40 / 333 \\
(12.0)\end{array}$ & $\begin{array}{l}31 / 330 \\
(9.4)\end{array}$ & \multicolumn{3}{|c|}{$0.56(0.29$ to 1.10$)$} & 0.094 \\
\hline Fruit and veg. & $\begin{array}{c}103 / 332 \\
(31.0)\end{array}$ & $\begin{array}{c}127 / 280 \\
(45.4)\end{array}$ & $\begin{array}{c}147 / 325 \\
(45.2)\end{array}$ & $\begin{array}{c}177 / 316 \\
(56.0)\end{array}$ & \multicolumn{3}{|c|}{0.79 (0.55 to 1.13$)$} & 0.198 \\
\hline Phys. activity & $\begin{array}{l}39 / 330 \\
(11.8)\end{array}$ & $\begin{array}{l}49 / 280 \\
(17.5)\end{array}$ & $\begin{array}{c}60 / 330 \\
(18.2)\end{array}$ & $\begin{array}{c}56 / 327 \\
(17.1)\end{array}$ & \multicolumn{3}{|c|}{$1.30(0.81$ to 2.08$)$} & 0.276 \\
\hline \multicolumn{9}{|c|}{ 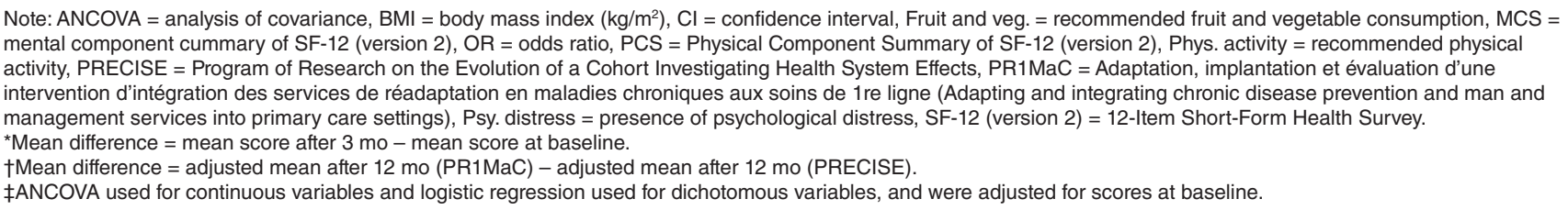 } \\
\hline
\end{tabular}


ing COPD and asthma, ${ }^{16,48}$ metabolic syndrome, ${ }^{49}$ kidney failure,${ }^{20}$ diabetes,${ }^{50}$ blood pressure control ${ }^{51}$ and people with risk factors. ${ }^{52}$ Interventions were based on different approaches, mainly self-management support and patient education. The outcomes used varied from study to study and included the use of health care services, quality of life, various physiologic indicators and modification of risk factors. All of the studies reported positive results in their respective outcomes.

\section{Limitations}

The main limitation of the study is the short period for follow-up for the RCT component. With a 3-month intervention to start behaviour change, the challenge was to make it sustainable over time. For this reason, follow-up responsibility was given to primary care physicians by transferring all information to the patients' medical records at the end of each intervention. Generalization of the results may be limited given the study eligibility based on selected conditions (type 2 diabetes, cardiovascular disease, COPD and asthma) or risk factors (smoking, obesity, hyperlipidemia, carbohydrate intolerance and metabolic syndrome). Other factors, such as cultural context and ethnicity, were not evaluated and could also limit generalization. Two additional limitations are no information was collected about health literacy, and we could not control the self-reported data for this variable.

The use of patient self-report questionnaires for outcomes may have introduced some desirability bias, but it is consistent with the use of a patient-centred approach. We acknowledge that participants could not be blinded to the intervention, and desirability bias could explain part of the changes observed in the immediate intervention group. In addition, the similar results in the triple experimental design suggests that they are not a consequence of desirability bias. Finally, one-third of the total number of patients referred by primary care providers to the research team declined to participate in the research. We did not collect information from these patients. We do not know what impact of this had on the composition of the sample of participants.

\section{Conclusion}

The evaluation of an innovative intervention for adapting and integrating chronic disease prevention and management services, which addressed more than 1 disease or risk factor into primary care settings, yielded positive and promising results. This type of intervention can be improved, and its introduction in the routine of primary care practice would help to achieve the primary care goal of high-quality care for patients with chronic diseases.

\section{References}

1. Global status report on noncommunicable diseases 2010. Geneva: World Health Organization; 2011. Available: www.who.int/nmh/publications/ncd_report_ full_en.pdf (accessed 2015 Aug. 18).

2. Mathers CD, Loncar D. Projections of global mortality and burden of disease from 2002 to 2030. PLoS Med 2006;3:e442.

3. Tan WS, Ding YY, Xia WC, et al. Effects of a population-based diabetes management program in Singapore. Am 7 Manag Care 2014;20:e388-98.

4. Johnson C, Ruisinger JF, Bates J, et al. Impact of a community-based diabetes self-management program on key metabolic parameters. Pharm Pract (Granada) 2014;12:499.
5. Samaan MC, Valencia M, Cheung C, et al. Design, implementation, and evaluation of a pediatric and adolescent type 2 diabetes management program at a tertiary pediatric center. 7 Multidiscip Healthc 2014;7:321-31.

6. Jameson JP, Baty PJ. Pharmacist collaborative management of poorly controlled diabetes mellitus: a randomized controlled trial. Am 7 Manag Care 2010;16:250-5.

7. Tang PC, Overhage JM, Chan AS, et al. Online disease management of diabetes: engaging and motivating patients online with enhanced resources-diabetes (EMPOWER-D), a randomized controlled trial. 7 Am Med Inform Assoc 2013;20:526-34.

8. Jain VV, Allison R, Beck SJ, et al. Impact of an integrated disease management program in reducing exacerbations in patients with severe asthma and COPD. Respir Med 2014;108:1794-800.

9. Rasberry CN, Cheung K, Buckley R, et al. Indicators of asthma control among students in a rural, school-based asthma management program. 7 Asthma 2014;51:876-85.

10. Hamar GB, Rula EY, Coberley C, et al. Long-term impact of a chronic disease management program on hospital utilization and cost in an Australian population with heart disease or diabetes. BMC Health Serv Res 2015;15:174.

11. Hendricks V, Schmidt S, Vogt A, et al. Case management program for patients with chronic heart failure: effectiveness in terms of mortality, hospital admissions and costs. Dtsch Arztebl Int 2014;111:264-70.

12. Housholder-Hughes SD, Ranella MJ, Dele-Michael A, et al. Evaluation of a postdischarge coronary artery disease management program. 7 Am Assoc Nurse Pract 2015;27:371-8.

13. Ryan JG, Buford U, Arias E, et al. Participation in and impact of a depression care management program targeting low-income minority patients in an urban community-based clinic. Clin Ther 2014;36:778-90.

14. Berghöfer A, Hartwich A, Bauer M, et al. Efficacy of a systematic depression management program in high utilizers of primary care: a randomized trial. BMC Health Serv Res 2012:12:298.

15. Simon GE, Ralston JD, Savarino J, et al. Randomized trial of depression follow-up care by online messaging. F Gen Intern Med 2011;26:698-704.

16. Lou $\mathrm{P}$, Chen $\mathrm{P}$, Zhang $\mathrm{P}$, et al. A COPD health management program in a community-based primary care setting: a randomized controlled trial. Respir Care 2015;60:102-12.

17. Fan VS, Gaziano JM, Lew R, et al. A comprehensive care management program to prevent chronic obstructive pulmonary disease hospitalizations: randomized, controlled trial. Ann Intern Med 2012;156:673-83.

18. Kruschitz R, Wallner-Liebmann SJ, Lothaller H, et al. Evaluation of a meal replacement-based weight management program in primary care settings according to the actual European Clinical Practice Guidelines for the Management of Obesity in Adults. Wien Klin Wochenschr 2014;126:598-603.

19. Dalton WT III, Schetzina KE, McBee MT, et al. Parent report of child's health-related quality of life after a primary-care-based weight management program. Child Obes 2013;9:501-8.

20. Bayliss EA, Bhardwaja B, Ross C, et al. Multidisciplinary team care may slow the rate of decline in renal function. Clin 7 Am Soc Nephrol 2011;6:704-10.

21. Villeneuve J, Genest J, Blais L, et al. A cluster randomized controlled Trial to Evaluate an Ambulatory primary care Management program for patients with dyslipidemia: the TEAM study. CMA7 2010;182:447-55.

22. Bex SD, Boldt AS, Needham SB, et al. Effectiveness of a hypertension care management program provided by clinical pharmacists for veterans. Pharmacotherapy 2011;31:31-8.

23. Nevedal DC, Wang C, Oberleitner L, et al. Effects of an individually tailored Web-based chronic pain management program on pain severity, psychological health, and functioning. 7 Med Internet Res 2013;15:e201.

24. Katon W, Russo J, Lin EH, et al. Cost-effectiveness of a multicondition collaborative care intervention: a randomized controlled trial. Arch Gen Psychiatry 2012;69:506-14.

25. Lin EH, Von Korff M, Peterson D, et al. Population targeting and durability of multimorbidity collaborative care management. Am $\mathcal{F}$ Manag Care 2014;20:887-95.

26. Morrin L, Britten J, Davachi S, et al. Alberta Healthy Living Program - a model for successful integration of chronic disease management services. Can 7 Diabetes 2013;37:254-9.

27. Fortin M, Chouinard MC, Bouhali T, et al. Evaluating the integration of chronic disease prevention and management services into primary health care. BMC Health Serv Res 2013;13:132.

28. Haggerty J, Fortin M, Beaulieu MD, et al. At the interface of community and healthcare systems: a longitudinal cohort study on evolving health and the impact of primary healthcare from the patient's perspective. BMC Health Serv Res 2010;10:258.

29. Bayliss EA, Ellis JL, Steiner JF. Subjective assessments of comorbidity correlate with quality of life health outcomes: Initial validation of a comorbidity assessment instrument. Health Qual Life Outcomes 2005;3:51.

30. Poitras ME, Fortin M, Hudon C, et al. Validation of the Disease Burden Morbidity Assessment by self-report in a French-speaking population. BMC Health Serv Res 2012;12:35.

31. Nolte S, Elsworth GR, Sinclair AJ, et al. The extent and breadth of benefits from participating in chronic disease self-management courses: a national patient-reported outcomes survey. Patient Educ Couns 2007;65:351-60. 
32. Osborne RH, Elsworth GR, Whitfield K. The Health Education Impact Questionnaire (heiQ): an outcomes and evaluation measure for patient education and self-management interventions for people with chronic conditions. Patient Educ Couns 2007;66:192-201.

33. Bélanger A, Hudon C, Fortin M, et al. Validation of a French-language version of the Health Education Impact Questionnaire (heiQ) among chronic disease patients seen in primary care: a cross-sectional study. Health Qual Life Outcomes 2015;13:64.

34. Sherer M, Maddux JE, Mercandante B, et al. The self-efficacy scale: construction and validation. Psychol Rep 1982;51:663-71.

35. Self-efficacy for managing chronic disease 6-item scale. Palo Alto (CA): Stanford Patient Education Research Center; 2004. Available: http://patienteducation. stanford.edu/research/secd6.html (accessed 2013 July 25).

36. Ware J, Kosinski M, Keller SD. A 12-item short-form health survey: construction of scales and preliminary steps of reliability and validity. Med Care 1996;34:220-33.

37. Brazier JE, Roberts J. The estimation of a preference-based measure of health from the SF-12. Med Care 2004:42:851-9.

38. Kessler RC, Barker PR, Colpe LJ, et al. Screening for serious mental illness in the general population. Arch Gen Psychiatry 2003;60:184-9.

39. Safran MA, Strine TW, Dhingra SS, et al. Psychological distress and mental health treatment among persons with and without active duty military experience, Behavioral Risk Factor Surveillance System, United States, 2007. Int 7 Public Health 2009;54(Suppl 1):61-7.

40. Indice de masse corporelle, selon le sexe. Québec: Santé et services sociaux Québec; 2011. Available: www.msss.gouv.qc.ca/statistiques/sante-bien-etre/ index.php?Indice-de-masse-corporelle-selon-le-sexe (accessed 2015 Aug. 18).

41. Maassen GH. The standard error in the Jacobson and Truax Reliable Change Index: the classical approach to the assessment of reliable change. 7 Int Neuropsychol Soc 2004;10:888-93.

42. Van Breukelen GJ. ANCOVA versus change from baseline: more power in randomized studies, more bias in nonrandomized studies [corrected]. 7 Clin Epidemiol 2006;59:920-5.

43. Moher D, Hopewell S, Schulz KF, et al.; Consolidated Standards of Reporting Trials Group. CONSORT 2010 explanation and elaboration: updated guidelines for reporting parallel group randomised trials. 7 Clin Epidemiol 2010;63:e1-37.

44. Sullivan GM, Feinn R. Using effect size - or why the $p$ value is not enough. 7 Grad Med Educ 2012;4:279-82.

45. Coventry P, Lovell K, Dickens C, et al. Integrated primary care for patients with mental and physical multimorbidity: cluster randomised controlled trial of collaborative care for patients with depression comorbid with diabetes or cardiovascular disease. BM7 2015;350:h638.

46. Hobbs N, Godfrey A, Lara J, et al. Are behavioral interventions effective in increasing physical activity at 12 to 36 months in adults aged 55 to 70 years? A systematic review and meta-analysis. BMC Med 2013;11:75.

47. Samsa G, Edelman D, Rothman ML, et al. Determining clinically important differences in health status measures: a general approach with illustration to the Health Utilities Index Mark II. Pharmacoeconomics 1999;15:141-55.

48. Hart MK, Millard MW. Approaches to chronic disease management for asthma and chronic obstructive pulmonary disease: strategies through the continuum of care. Proc Bayl Univ Med Cent 2010;23:223-9.

49. Blonstein AC, Yank V, Stafford RS, et al. Translating an evidence-based lifestyle intervention program into primary care: lessons learned. Health Promot Pract 2013;14:491-7.

50. Huang MC, Hsu CC, Wang HS, et al. Prospective randomized controlled trial to evaluate effectiveness of registered dietitian-led diabetes management on glycemic and diet control in a primary care setting in Taiwan. Diabetes Care 2010;33:233-9.
51. Sillah A, Sidebottom AC, Boucher JL, et al. Program participation and blood pressure improvement in the Heart of New Ulm Project, Minnesota, 20092011. Prev Chronic Dis 2014;11:E48.

52. Eriksson KM, Westborg CJ, Eliasson MC. A randomized trial of lifestyle intervention in primary healthcare for the modification of cardiovascular risk factors. Scand 7 Public Health 2006;34:453-61.

Affiliations: Département de médecine de famille et de médecine d'urgence (Fortin), Université de Sherbrooke, Sherbrooke, Qué.; Département des sciences de la santé (Chouinard, Dubois), Université du Quebec à Chicoutimi, Chicoutimi, Qué.; Centre intégré universitaire de santé et de services sociaux du Saguenay-Lac-Saint-Jean (Bélanger), Chicoutimi, Qué.; Département de médecine de famille et médecine d'urgence (Almirall, Bouhali), Université de Sherbrooke, Sherbrooke, Qué.; Facultés de Médecine et sciences de la santé (Sasseville), Université de Sherbrooke, Sherbrooke, Qué.

Contributors: Martin Fortin, Maud-Christine Chouinard, Marie-France Dubois and Martin Bélanger identified the need for this study and contributed to its conception and design. José Almirall and Tarek Bouhali conducted the data analysis under the supervision and guidance of MarieFrance Dubois and Martin Fortin. Maud-Christine Chouinard, Martin Bélanger and Maxime Sasseville also contributed to the analysis and interpretation of data. All of the authors contributed to the first draft and had full access to all of the data. All of the authors reviewed the manuscript critically for intellectual content, gave final approval of the version to be published and agreed to act as guarantors of the work.

Funding: Martin Fortin holds the Research Chair on Chronic Diseases in Primary Care (funded by La fondation de ma vie and Université de Sherbrooke, Sherbrooke, Que.). The authors received support from Fonds Pfizer-Fonds de Recherche du Québec en santé (FRQS)-Ministère de la Sante et des Services sociaux Maladies chroniques, Centre intégré universitaire de santé et de services sociaux du Saguenay-Lac-Saint-Jean and Université du Québec à Chicoutimi. The FRQS peer reviewed the protocol and managed the funding. None of the funding entities had any role in preparing, reviewing or approving the manuscript.

Acknowledgements: The authors gratefully acknowledge the contribution of all participants including patients, their family members, health care services managers and professionals. We also acknowledge the extended research team members for their contributions in the conception and the conduct of the study. We thank the clinical team members and the 8 participating clinics for their help and advice with our research project. We also thank the members of the Trajectoire des services de services de réadaptation integrés pour les maladies chroniques and all professionals of specialized health care services of Centre intégré universitaire de santé et de services sociaux du Saguenay-Lac-Saint-Jean for their help and advice in the development of the clinical interventions. This study was made possible by the dedication of the employees of the Research Chair on Chronic Diseases in Primary Care.

Supplemental information: For reviewer comments and the original submission of this manuscript, please see www.cmajopen.ca/content/4/4/ E588/suppl/DC1 